\title{
Necrotizing Fasciitis of the Lower Limb - A Prospective Study of Prognostic Factors Affecting Mortality
}

\author{
EK Chee, MS Ortho, MK Kwan*, MS Ortho, EH Khoo**, MS Ortho \\ Department of Orthopaedic Surgery, Kuala Lumpur Hospital, Malaysia \\ *Department of Orthopaedic Surgery, University Malaya Medical Centre, Kuala Lumpur, Malaysia \\ **Department of Orthopaedic Surgery, Seberang Jaya Hospital, Penang, Malaysia
}

\begin{abstract}
Necrotizing fasciitis is a life and limb threatening soft tissue infection with a high mortality rate. This study tries to identify the possible risk factors that contribute to mortality in patients with necrotizing fasciitis involving a lower limb. We prospectively reviewed 41 patients that presented with necrotizing fasciitis of the lower limb over a period of one year. Results show that the mortality rate for necrotizing fasciitis of the lower limb is quite high at $19.5 \%$. Comparison among necrotizing fasciitis patients reveals that higher mortality rate is seen among those patients with advanced age and those presented with initial high pre-operative creatinine levels. Sex, pre-morbid diabetes mellitus, duration from initial symptoms to presentation for treatment and presence of streptococcus group A were not associated with an increased mortality rate. Neither were admission vital signs, subcutaneous gas on radiograph, prior antibiotic treatment on admission or clinical note of bullae formation.
\end{abstract}

Key Words:

Necrotizing fasciitis, Lower limb, Risk factors

\section{INTRODUCTION}

Necrotizing fasciitis is an uncommon but potentially limb and life threatening soft tissue infection. It has been recognized clinically since the time of Hippocrates ${ }^{1}$, and first documented in modern surgical literature by Joseph Jones as "hospital gangrene" ${ }^{2}$. In the 1990's it became popularly known in media as the "flesh-eating bacteria" disease $^{3}$. This condition is associated with a high mortality rate, ranging from $9 \%$ to $29 \%{ }^{4-7}$. Various risk factors for mortality have been analysed, however most of the literature studies combined incidence of necrotizing fasciitis involving both upper limb and lower limbs. This study particularly looks into the risk factors involving the lower limbs.

\section{MATERIALS AND METHODS}

This was a prospective study of risk factors for mortality in patients diagnosed with necrotizing fasciitis of a lower limb.
All the patients were admitted and treated in the orthopaedic ward of Tengku Ampuan Rahimah Hospital and University Malaya Medical Centre (tertiary state government hospital and university teaching hospital respectively) from November 2004 till October 2005. Diagnosis was made by combination of clinical and gross anatomical findings during surgery. We excluded those patients in which treatment were performed in other hospitals and transferred in for further management and those who took part in at-own-risk discharge or transferred out to other hospitals pre- or post-treatment.

Demographic patient data were collected. Patients were interviewed by the researcher regarding history of preexisting diabetes mellitus, any prior antibiotics used before admission and the duration of symptoms prior to admission. Systolic and diastolic blood pressure and temperature on the day of admission were recorded. Thorough physical examination was performed to look for any bullae formation on the lower limbs. On admission, patients blood testing included haemoglobin, platelets, urea, sodium, potassium and creatinine levels. Radiograph of the involved limb were taken on admission to look for subcutaneous gas formation. Treatments were then started that included haemodynamic stabilization, broad spectrum antibiotics and aggressive wound debridement. Amputation was performed if the underlying infection was uncontrollable. Culture and sensitivities were taken from the infected wound during the debridement or amputation particularly to test for Strep group A organisms. The wound was inspected 24 hours postdebridement and re-debridement was performed periodically, as necessary, until all necrotic tissue was removed. The wound was dressed using normal saline soaked gauze in combination with paraffin gauze. Wound closure was performed as soon as the wound was healthy, normally by split skin grafting. Antibiotics were adjusted as soon as the culture and sensitivity results were available.

Variables were compared for survivors and non-survivors, using Pearson chi-square test for discrete data and student's t-test for continuous data. $\mathrm{P}$ value of $<0.05$ was significant. Univariate analysis was conducted comparing variables with mortality. Data were analyzed using SPSS, Version 12 for Windows. 
Table I: Summary of variables that determine the risk factors for mortality in patients with necrotizing fasciitis of the lower limb

\begin{tabular}{|lccc|}
\hline Variable & $\begin{array}{c}\text { Surviving patients } \\
(\mathbf{n}=33)\end{array}$ & $\begin{array}{c}\text { Non-surviving patients } \\
(\mathbf{n}=8)\end{array}$ & $\begin{array}{c}\mathbf{P} \\
\text { value }\end{array}$ \\
\hline Age (years) & $54.2 \pm 11.1$ & $63.6 \pm 9.9$ & $* 0.036$ \\
Sex M:F & $26: 7(78.8 \%)$ & $4: 4(50 \%)$ & 0.178 \\
Co-morbid with Diabetes & 29 & 5 & 0.120 \\
Duration from onset of symptoms to wound & $7.5 \pm 2.9$ & $6.3 \pm 2.2$ & 0.423 \\
debridement (days) & & & \\
Prior antibiotic treatment & 22 & 6 & 1.000 \\
Temperature on admission $\left({ }^{\circ} \mathrm{C}\right)$ & $37.5 \pm 0.8$ & $37.1 \pm 0.5$ & 0.184 \\
Systolic BP on admission $(\mathrm{mmHg})$ & $123.4 \pm 21.4$ & $129.1 \pm 28.4$ & 0.530 \\
Diastolic BP on admission $(\mathrm{mmHg})$ & $73.4 \pm 14.1$ & $67.3 \pm 17.7$ & 0.290 \\
Bullae formation & 8 & 4 & 0.202 \\
Plain radiograph with subcutaneous gas & 10 & 1 & 0.412 \\
Strep group A infection & 3 & 3 & 0.077 \\
Preop WBC $\left(\mathrm{x} 10^{3} / \mu \mathrm{L}\right)$ & $19.3 \pm 6.4$ & $20.6 \pm 7.6$ & 0.631 \\
Preop haemoglobin $(\mathrm{g} / \mathrm{dL})$ & $11.0 \pm 2.1$ & $10.5 \pm 1.8$ & 0.515 \\
Preop platelet $\left(\mathrm{x} 10^{3} / \mathrm{\mu L}\right)$ & $333.6 \pm 132.5$ & $250.1 \pm 41.6$ & 0.089 \\
Preop sodium $(\mathrm{mEq} / \mathrm{L})$ & $128.0 \pm 5.8$ & $129.9 \pm 3.7$ & 0.378 \\
Preop potassium $(\mathrm{mEq} / \mathrm{L})$ & $4.2 \pm 0.7$ & $4.7 \pm 7.3$ & 0.066 \\
Preop creatinine $(\mu \mathrm{mol} / \mathrm{L})$ & $130.2 \pm 85.0$ & $271.1 \pm 174.9$ & $* 0.038$ \\
Preop urea $(\mathrm{mmol} / \mathrm{L})$ & $11.5 \pm 11.6$ & $19.6 \pm 6.3$ & 0.064 \\
\hline
\end{tabular}

*Statistically significant $(P<0.05)$

\section{RESULTS}

This study consists of 46 patients with 34 males (74\%) and 12 females $(26 \%)$. Five patients were excluded from the study, thus, a total of 41 patients were available for statistical analysis. Out of the five patients who were excluded, two patients were referred to us after wound debridement was performed in other hospitals. Two patients discharge themselves against medical advice before wound debridement . One patient discharged himself against medical advice, immediately after wound debridement.

There were 33 survivors and eight deaths, resulting in a mortality rate of $19.5 \%$. For those who survived, 26 are male $(79 \%)$ and seven are female $(21 \%)$. For non-survivors there are four male and four female. The mean age for the 33 patients who survived was $54.2 \pm 11.1$ years (range 33-74) and 63.6 \pm 9.9 years (range 37-90) for those who died. The mean age difference between these two is statistically significant $(\mathrm{P}=0.04)$. There is no statistically significant difference between the risks of mortality between male and female. In the current study, up to $85 \%$ of the patients with diabetes mellitus survive and having the disease does not increase the risk of mortality. The mean duration from initial symptoms to wound debridement was $7.5 \pm 2.9$ days for those who survived and $6.3 \pm 2.2$ for those who died, a statistically insignificant difference $(\mathrm{P}=0.43)$. There was a time span of $9 \pm 5.3$ days for surviving patients and 5 days for non-survival from initial symptoms to amputation, a statistically insignificant difference. Prior oral antibiotic treatment before admission was noted in up to $21 \%$ of non-surviving patients and $79 \%$ of surviving patients. The use of antibiotic prior to admission however did not affect mortality outcomes.
The mean temperature on admission for both groups was not significantly different - surviving patients has a mean temperature of $37.5 \pm 0.8^{\circ}$ as compared to non-surviving patients of $37.1 \pm 0.5^{\circ} \quad(p=0.184)$. Mean systolic blood pressure was higher, but not statistically significantly higher for non-surviving patients $(129 \pm 28 \mathrm{mmHg})$ as compared to surviving patients $(123 \pm 21 \mathrm{mmHg})$. Mean diastolic pressure was lower for non-surviving patients $(67 \pm 17 \mathrm{mmHg})$ as compared to surviving patients of $(73 \pm 14 \mathrm{mmHg})$, again not statistically significant. Out of the 41 patients, 11 presented with subcutaneous gas on plain radiograph, and of the 11 , only 1 patient died; this was therefore not a statistically significant contributing factor to mortality. Out of the 12 patients who presented with bullae, $33 \%(n=4)$ of them died, a statistically insignificant proportion.

Of those with Streptococcus group A infection, non-survival was noted in up to $50 \%$ of cases; however, this is statistically not significant due to the small number of cases with that particular infection. Pre-operative total white blood count (TWBC) was high in both groups of patient (19.3 \pm 6.4 for surviving patient and $20.6 \pm 7.6$ for non surviving patient). Preoperative urea levels were higher for non-surviving patients at $19.6 \pm 6.3$ as compare to surviving patient at $11.5 \pm 11.6$, but this was not statistically significant. Sodium levels were low preoperatively both in surviving and non-surviving patients at level of $128.0 \pm 5.8$ and $129.9 \pm 3.7$ respectively. The preoperative creatinine level was significantly higher in nonsurviving patients $(271.1 \pm 174.9)$ as compared to surviving patients $(130.2 \pm 85.0)$ and this is statistically significant $(\mathrm{p}=0.038)$. Pre-operative haemoglobin, platelet and potassium level differences were not statistically significant when comparing survivors to non-survivors. 


\section{DISCUSSION}

Necrotizing fasciitis is an infection of the subcutaneous tissue and fascia that is associated with a high mortality rate. In 1924, Meleney ${ }^{5}$ noted a mortality rate of $20 \%$ out of 20 patients. The mortality rate of $19.5 \%$ in the present series is slightly lower than the cumulative mortality of $34 \%$ as reported in the Mchenry et al. study ${ }^{7}$. Wong et al., ${ }^{4}$ in their series of 89 patients, $70 \%$ involving lower limbs, have a mortality rate of $21.3 \%$. Singh et al., ${ }^{8}$ in their series of 55 patients (31 involving lower limbs) reported a mortality of $27.2 \%$. Tang et al., ${ }^{9}$ with 24 patients with necrotizing fasciitis of the limbs, in which 12 involved the lower limbs, reported a mortality of $33.3 \%$. As we know necrotizing fasciitis of the lower limbs are more amenable for local control as amputation can be performed to control the local effect of the disease, whereas necrotizing fasciitis that involves trunk and genitourinary systems is more difficult to control since wound debridement hindered and not as thorough because it involves vital organs. Thus, lower limb involvement gives a more favourable outcome and a lower mortality rate.

In the current study, a comparison of survivors and nonsurvivors in terms of risk factors for mortality yields only age and high pre-operative creatinine levels as statistically significant determinants. Several authors ${ }^{2,3,10,11}$ reported that patients above the age of 60 were associated with higher mortality. Other confounding factors must be taken into consideration as elderly patients are predisposed to illnesses such as diabetes mellitus and renal failure and their immunological status is generally poorer, all of which may contribute to the higher mortality rate. As the current study is limited by the small sample available, we were unable to carry out multivariate analysis which would have given more reliable statistical data. We do not find sex as a determinant factor for mortality, contrary to results reported by Elliot et $a l .{ }^{10}$. Diabetes mellitus has been identified as a co-morbidity that affects mortality in studies by Brand et al. and Elliot et $a l{ }^{2,10}$, however we did not such a correlation.
There were no significant effect of admission temperature on mortality in the present study, but this is contrary to a report by Bosshardt et al. ${ }^{14}$ in which high admission temperature was identified as a risk factor of mortality. It is possible that non-surviving patients may be immunocompromised and less able to mount an inflammatory response such as an increase in temperature. We do not find that admission blood pressure affected mortality, contrary to reports by Bosshart et al. and Fustes-Morales et al. who identified low blood pressure as a determinant for mortality ${ }^{14,15}$. High preoperative creatinine levels were identified as a significantly contributory factor to mortality in the current study and may be related to some degree of renal impairment. However we cannot differentiate whether the condition is due to necrotizing fasciitis or pre-existing renal disease because most of these patients also had underlying diabetes mellitus predisposing them to nephropathy.

Initial presentation of necrotizing fasciitis is easily confused with other milder soft tissue infections such as cellulitis and abscess. Unfortunately, this can delay definitive treatment of debridement or amputation. Our study does not show any significant effect of duration from symptom to wound debridement to affect mortality, however Eckmann et al. ${ }^{12}$ noted those with a duration of initial symptoms to surgical treatment of more than 5 days were in fact associated with a higher mortality rate. Although little can be done to influence the time between a patient development of symptoms and receipt of medical attention except to increase public awareness through education, measures can be taken to hasten the diagnosis and early operative debridement. Wong et al. ${ }^{13}$ developed a screening system for necrotizing fasciitis with a high predictive value that is helpful in making an early diagnosis, leading to situations where definitive treatment can be carried out as early as possible.

\section{CONCLUSION}

The mortality rate for necrotizing fasciitis of the lower limb remains high at $19.5 \%$. Patients with advanced age and high pre-operative creatinine levels have higher risk of mortality. 


\section{REFERENCES}

1. Trent JT, Kirsner RS. Diagnosing necrotizing fasciitis. Adv Skin Wound Care 2002; 15(3): 135-8.

2. Brandt MM, Corpron CA, Wahl WL. Necrotizing soft tissue infections: a surgical disease. Am Surg 2000; 66(10): 967-70; discussion 70-1.

3. Childers BJ, Potyondy LD, Nachreiner R, Rogers FR, Childers ER, Oberg KC, et al. Necrotizing fasciitis: a fourteen-year retrospective study of 163 consecutive patients. Am Surg 2002; 68(2): 109-16.

4. Wong CH, Chang HC, Pasupathy S, Khin LW, Tan JL, Low CO. Necrotizing fasciitis: clinical presentation, microbiology, and determinants of mortality. J Bone Joint Surg 2003; 85A(8): 1454-60.

5. Meleney F. Hemolytic streptococcus gangrene. Arch Surg 1924; 9: 317-31.

6. Wilson B. Necrotizing fasciitis. Am Surg 1952 Apr;18(4): 416-31.

7. McHenry CR, Piotrowski JJ, Petrinic D, Malangoni MA. Determinants of mortality for necrotizing soft-tissue infections. Ann Surg 1995; 221(5): 558-63; discussion 63-5.

8. Singh G, Ray P, Sinha SK, Adhikary S, Khanna SK. Bacteriology of necrotizing infections of soft tissues. Aust N Z J Surg 1996; 66(11): 747-50.

9. $\quad$ Tang WM, Ho PL, Fung KK, Yuen KY, Leong JC. Necrotising fasciitis of a limb. J Bone Joint Surg 2001; 83-B(5): 709-14.

10. Elliott DC, Kufera JA, Myers RA. Necrotizing soft tissue infections. Risk factors for mortality and strategies for management. Ann Surg 1996; 224(5): 672-83.

11. Eckmann C, Kujath P, Shekarriz H, Staubach KH. Clostridium myonecrosis as a sequelae of intramuscular injections--description of 3 fatal outcomes. Langenbecks Arch Chir Suppl Kongressbd 1997; 114: 553-5.

12. Eckmann C K, P, Psathakis D. Results of standardized therapy of necrotizing fasciitis. Br J Surg 1997; 88. Supplement 2.

13. Wong CH, Khin LW, Heng KS, Tan KC, Low CO. The LRINEC (Laboratory Risk Indicator for Necrotizing Fasciitis) score: a tool for distinguishing necrotizing fasciitis from other soft tissue infections. Crit Care Med 2004; 32(7): 1535-41.

14. Bosshardt TL HV, Organ CH Jr. Necrotizing soft-tissue infections. Archives Surgery 1996; 131(8): 846-54.

15. Fustes MA, Gutierrez CP, Duran MC, Orozco CL, Tamayo SL, Ruiz MR. Necrotizing fasciitis: report of 39 pediatric cases. Arch Dermatol 2002; 138(7): 893-9. 